\title{
Synthesis of a novel poly (arylene ether ketone) and its conducting composites with polypyrrole
}

\author{
F. Selampinar ${ }^{a}$, U. Akbulut ${ }^{\text {a }}$, E. Yildiz ${ }^{b}$, A. Güngör ${ }^{b}$, L. Toppare ${ }^{c, *}$ \\ "Department of Chemistry, Middle East Technical University, 0653I Ankara, Turkey \\ ${ }^{\mathrm{b}}$ Research Institute for Material and Chemical Technologies, Turkish Scientific and Technical Research Council, Marmara Research Center, \\ 41470 Gebze, Kocaeli, Turkey \\ 'Department of Chemistry, Bilkent University, 06533 Ankara, Turkey
}

Received 27 September 1996; accepted 2 May 1997

\begin{abstract}
The synthesis of a 1,3-bis (4-fluorobenzoyl)-5-tert-butyl benzene and hexafluoro bisphenol A based poly (arylene ether ketone) (PEK) was described. The electrically conductive composites of polypyrrole (PPy) and PEK were formed by electropolymerization of pyrrole on a PEK coated platinum electrode in a medium containing water and $p$-toluenesulfonic acid as the solvent and the electrolyte, respectively. The electrical conductivity of the composites was found to be between 1 and $4 \mathrm{~S} / \mathrm{cm}$. The polypyrrole/poly (ether ketone) composites were characterized by scanning electron microscopy, FT-IR and thermal analyses (TGA, DSC). C 1997 Elscvicr Scicnce S.A.
\end{abstract}

Keywords: Polypyrrole and derivatives; Poly (arylene ether ketone); Bilayer; $p$-Toluene sulfonic acid; Conducting composites

\section{Introduction}

In recent years, the electrical and optical properties of conducting polymers synthesized by electrochemical polymerization have been studied in great detail. Considerable attention has been paid to the polymers of five-membered heterocycles such as polypyrrole, polythiophene and polyacetylene, since they can substitute for conductors and semiconductors in a wide variety of electric and electronic devices. The features of conducting polymers such as reversibility, availability in film form and good environmental stability enhance their potential use in practical applications.

One of the most widely studied polymers, polypyrrole (PPy), can be obtained chemically or electrochemically. The electrochemical polymerization of pyrrole has been extensively studied as it is easily obtained in the form of freestanding films, and has good environmental stability and conductivity. It has been shown that PPy has many technological applications as secondary batteries [1-3], electrochromic display devices [4,5], light-emitting diodes [6,7], capacitors [8,9], sensors [10-12] and enzyme electrodes [13-15].

Since conjugated conducting polymers without long flexible side chains are brittle, especially after doping, blending

\footnotetext{
Corresponding author.
}

them with insulating polymers in order to improve their mechanical properties and processability has been attempted. Several efforts have been made to combine these polymers with ductile or tough materials. The most successful way of forming composites was found to be the electropolymerization of the conducting component on an electrode coated with the insulating polymer. Among these, the electrochemically polymerized composites of pyrrole have attained much attention due to its excellent flexibility, ease of doping, good conductivity and stability under normal environmental conditions. As the host polymers, poly (vinyl chloride) $[16,17]$, poly (vinyl alcohol) [18], polycarbonate [19], polyamide [20], polyimide [21], polyindene [22], Nafion [23] and poly ( $p$-phenylene terephthalamide) [24] were cited.

The electrochemical synthesis of PPy in the presence of surfactants has been described by several authors [25-28] These compounds allow work in aqueous solutions and thus, stable, conductive, flexible, electroactive and electrochromic PPy films can be produced.

Poly (arylene ether)s are well accepted as high performance engineering thermoplastics and offer excellent combinations of chemical, physical and mechanical properties at ambient and elevated temperatures [29,30]. ICI's Victrex ${ }^{\mathrm{TM}}$, poly(ether sulfone) (PES) and semicrystalline poly(ether ether ketone) Victrex ${ }^{\mathrm{TM}}$ (PEEK), Amoco's Udel ${ }^{\mathrm{TM}}$ poly (sulfone) and Kadel ${ }^{\mathrm{TM}}$ poly(ketone) are commercially 
available and are important high performance engineering polymers. They are used in a variety of applications such as coatings, adhesives, matrix resins for advanced composites, toughening agents and ultrafiltration membranes.

The method most frequently utilized for the preparation of poly (arylene ether) $s$ is aromatic nucleophilic substitution of fluorides or chlorides from aromatic bishalides and bisphenolates. The aromatic bis(arylhalide)s are activated toward nucleophilic substitution by the carbonyl or sulfone groups [31-33]. Unless carefully designed, however, poly (ether ether ketone)s often exhibit low solubility in common organic solvents at high molding temperatures. Thereforc, the preparation of soluble or processable poly(arylene ether) $s$ without sacrificing their desirable properties has been of major research interest. The concepts for structural modifications such as the introduction of flexible bridging linkages [34] or meta-oriented phenylene rings [35] into the polymer backbone and incorporation of methyl substituted [36.37] or bulky substituents [38] along the polymer chain have been used to enhance the solubility and the processability. Also, several researchers have reported that introduction of hexafluoroisopropylidene groups between rigid phenylene rings improves the solubility $[39,40]$.

This article deals with the synthesis of a soluble, processable, aromatic polyether ketone from t-butyl substituted activated bishalide and hexafluoroisopropylidene bis phenol A in order to use it in the preparation of conducting polymer composites of PPy.

\section{Experimental}

\subsection{Materials}

5-Tert-butyl isophthalic acid (Amoco) and thionyl chloride (Merck) were used without further purification. Fluorobenzene (Mallincrot) and dimethylformamide (Merck) were dried over a $3 \AA$ molecular sieve. Toluene (Merck) was purified by washing it twice with sulfuric acid, next with water, then with $5 \%$ sodium bicarbonate solution and finally with water again. It was dried over calcium sulfate, phosphorus pentoxide and distilled over sodium. Dimethylacetamide (DMAc) (Aldrich) was distilled over phosphorus pentoxide under reduced pressure. 4,4'-Hexafluoroisopropylidene bisphenol ( $6 \mathrm{~F}$ bisphenol A) (Aldrich) was purified by sublimation.

Pyrrole (Merck) was distilled before use. The $p$-toluene sulfonic acid (Aldrich) and chloroform (Merck) were used as received.

\subsection{Monomer synthesis and characterization}

\subsubsection{Synthesis of 5-tert-butyl isophthalic acid chloride}

A mixture of 5-tert-butyl isophthalic acid $(0.0899 \mathrm{~mol})$ and $\mathrm{SOCl}_{2}(1.3767 \mathrm{~mol})$ and a catalytic amount of dimcthylformamide was stirred at reflux, under $\mathrm{N}_{2}$ atmosphere for
$6 \mathrm{~h}$. Excess $\mathrm{SOCl}_{2}$ was distilled away under reduced pressure. The acid chloride was used without further purification [41].

\subsubsection{Synthesis of 1,3-bis (4-fluorobenzoyl)-5-tert-butylben- zene (TBFBB)}

A mixture of 5-tert-butyl isophthalic acid chloride $(0.0772$ $\mathrm{mol})$ and fluorobenzene $(0.9590 \mathrm{~mol})$ was stirred under $\mathrm{N}_{2}$ atmosphere and cooled in an ice-water bath. Anhydrous $\mathrm{AlCl}_{3}(0.1591 \mathrm{~mol})$ was added slowly to the reaction mixture and reffuxed for $8 \mathrm{~h}$. Then the reaction mixture was cooled to room temperature and poured into a mixture of crushed ice, hydrochloric acid and dichloromethane (150/30/250 $\mathrm{ml}$ ). The organic layer was washed with distilled water, then neutralized with an aqueous solution of $\mathrm{NaHCO}_{3}(10 \%)$ and washed again with distilled water. The organic layer was dried over $\mathrm{MgSO}_{4}$, filtered and condensed by vacuum distillation [41]. The solid product was three times recrystallized from hexane to yield white crystals (97\%); m.p. 114-115 ${ }^{\circ} \mathrm{C} .{ }^{1} \mathrm{H}$ NMR (200 MHz, $\mathrm{CDCl}_{3}$ ) $\delta: 1.40$ ( $\mathrm{s}, 9 \mathrm{H}$, t-butyl); 7.18 (dd $4 \mathrm{H}$, o to $\mathrm{F}$ ); 7.87 (m, $5 \mathrm{H}, \mathrm{m}$ to $\mathrm{F}$, and $1 \mathrm{H}$, p to tbutyl); 8.05 ( $\mathrm{s}, 2 \mathrm{H}$ o to t-butyl). FT-IR $\left(\mathrm{KBr}, \mathrm{cm}^{-1}\right): 2964-$ 2862 (aliphatic C-H stretching), 3047-3069 (aromatic C$\mathrm{H}$ stretching), 1660 ( $\mathrm{C}=\mathrm{O}$ stretching), 1228 (C-F stretching). MS $\left(\mathrm{El}^{+}, m / z\right)$ : $378.1\left(\mathrm{M}^{+}\right)$. Anal. Calc. for $\mathrm{C}_{24} \mathrm{H}_{20} \mathrm{O}_{2} \mathrm{~F}_{2}: \mathrm{C}, 76.17 ; \mathrm{H}, 5.32$. Found $\mathrm{C}: 76.15, \mathrm{H}, 5.31 \%$.

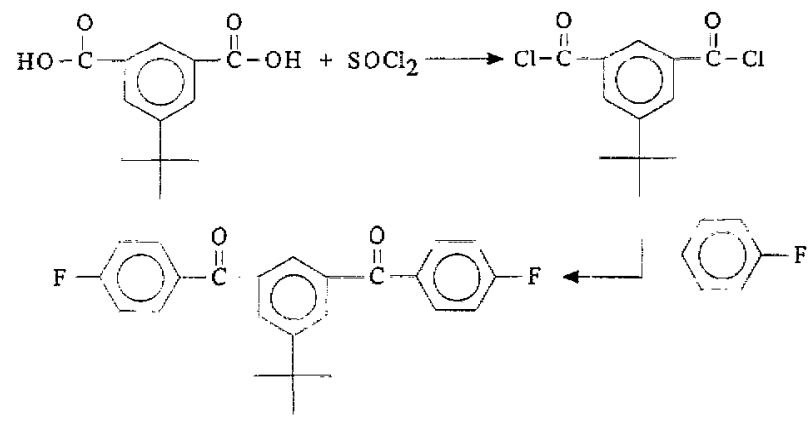

\subsection{Synthesis of poly(arylene ether ketone) (PEK)}

A $100 \mathrm{ml}$ three-necked round-bottomed flask equipped with a Dean Stark trap, $\mathrm{N}_{2}$ inlet, condenser was charged with TBFBB $(0.01321 \mathrm{~mol}), 6 \mathrm{~F}$ bisphenol A $(0.01321 \mathrm{~mol})$, anhydrous $\mathrm{K}_{2} \mathrm{CO}_{3}(0.0198 \mathrm{~mol}), 22.6 \mathrm{ml}$ DMAc and $8.2 \mathrm{ml}$ toluene. The temperature of the reaction mixture was slowly raised to $120^{\circ} \mathrm{C}$ and refluxed for $8 \mathrm{~h}$. The water generated during the formation of the phenate was removed by azeotrope (toluene) and the reaction was maintained at $160^{\circ} \mathrm{C}$ for $8 \mathrm{~h}$. Toluene was distilled out, the reaction mixture was cooled to room temperature and the polymer was obtained by precipitating it from methanol/water mixture ( $1 / 1$ vol./ vol.). Dried polymer was redissolved in chloroform and precipitated from methanol. Finally, the polymer was dried at $105^{\circ} \mathrm{C}$ for $12 \mathrm{~h}$ under vacuum (solution viscosity: 0.7553 $\left.\mathrm{dl} / \mathrm{g}, M_{\mathrm{w}}: 192 \times 10^{3}, M_{\mathrm{n}}: 65.5 \times 10^{3}, M_{\mathrm{w}} / M_{\mathrm{n}}: 3.0\right)$. 


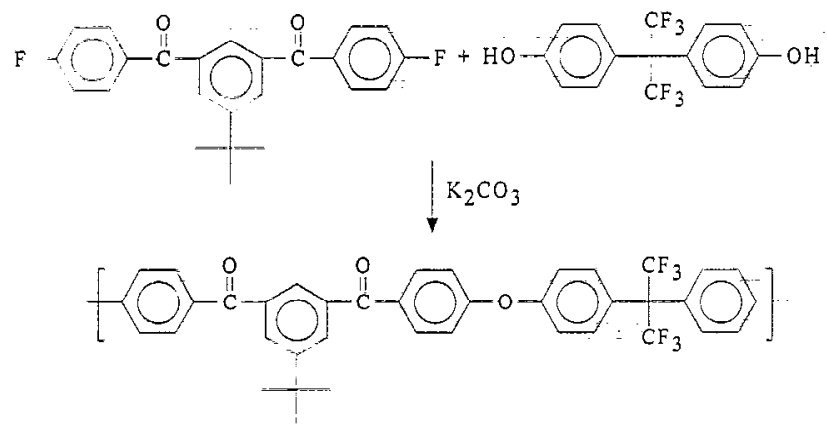

\subsection{Preparation of PEKJPPy composites}

Composite films were prepared potentiostatically in a three-electrode cell. The working electrode and the counter electrode were platinum foils of $1.5 \mathrm{~cm}^{2}$ and the reference electrode was $\mathrm{Ag} / \mathrm{Ag}^{+}$. The potentiostat used was a Wenking POS-73. Electrochemical polymerization of pyrrole was carried out in distilled water containing $0.05 \mathrm{~mol} / 1$ pyrrole and $0.1 \mathrm{~mol} / 1 p$-toluenesulfonic acid. The solutions were purged with $\mathrm{N}_{2}$ for 10-15 min before polymerization and a blanket of nitrogen was used during experiments. A PEK coated $\mathrm{Pt}$ electrode was prepared by depositing a $1 \mathrm{wt}$.\% solution of PEK in chloroform onto a Pt foil and allowing the solvent to evaporate completely. Thin films of dried polymer on $\mathrm{Pt}$ electrode were directly used for electrochemical polymerization. Syntheses of composites were carried out at a constant potential of $0.5 \mathrm{~V}$ relative to the $\mathrm{Ag} / \mathrm{Ag}^{+}$reference electrode. After a suitable polymerization period, the electrodes were removed from the electrolysis medium and washed with acetonitrile and allowed to dry under vacuum.

Blank runs were also carried out to ensure that there were no changes in the weight of the PEK coated electrode. It was observed that PEK did not undergo oxidation during the polymerization; in order to prove this, FT-IR spectra of the films were taken before and after electrolyses.

The weight percentage of PPy in the composites was determined gravimetrically. PPy/PEK samples were peeled from the electrode, thoroughly washed with water and then with acetonitrile to remove the supporting electrolyte on the surface, and then dried under vacuum before characterization.

\subsection{Cyclic voltammetry $(\mathrm{CV})$ experiments}

For CV studies an electrolyte solution of $0.1 \mathrm{~mol} / 1 \mathrm{p}$-TSA in water was used in all experiments. All solutions in the cell were purged with $\mathrm{N}_{2}$ for 10-15 min before each experiment and a blanket of nitrogen was used during the $\mathrm{CV}$ runs. Platinum wires were used both as counter and working electrodes and $\mathrm{Ag} / \mathrm{Ag}^{+}$was used as the reference electrode. The polymer (PEK) was coated onto the working electrode by dipping the Pt wire electrode in the 1 wt.\% PEK solution. The dried $\mathrm{PEK}$ polymer on the $\mathrm{Pt}$ working electrode was cycled repeatedly between -0.2 and +1.2 (versus $\mathrm{Ag} / \mathrm{Ag}^{+}$).

\subsection{Conductivity measurements}

Several films with different PPy contents were used for conductivity measurements. The conductivity measurements were carried out by using a four-point probe.

\subsection{Thermal analyses}

Thermal characterization of the PEK and the composites was carried out using a DuPont modular thermal analyzer system in conjunction with a 951 thermal gravimetric analyzer and 910 differential scanning calorimeter. Thermal gravimetry experiments were done under a dry nitrogen purge. A constant heating rate of $10^{\circ} \mathrm{C} / \mathrm{min}$ was used.

\subsection{FT-IR spectroscopy}

A Nicolet 510-P FT-IR instrument was used to obtain the spectra of $\mathrm{PEK}$ and composites as $\mathrm{KBr}$ pellets.

\subsection{NMR spectroscopy}

A Bruker AC 200L spectrometer operating at 200.132 $\mathrm{MHz}$ for ${ }^{1} \mathrm{H}$ was used to characterize the PEK.

\subsection{Elemental analysis}

Elemental analysis of PEK was obtained by a Carlo-Erba 1106 elemental analyzer.

\subsection{Scanning electron microscopy (SEM)}

SEM micrographs of electrochemically produced composites and pure PPy were taken by a JEOL JSM 6400 scanning electron microscope.

\subsection{Molecular weight measurements}

The number and weight average molecular weights of PEK were determined by a Waters 510 HPLC pump in conjunction with a Waters 410 refractometer.

\section{Results and discussion}

It was claimed that, for the reasons of low solubility and high acidity of the solution, $p$-toluene sulfonic acid (PTSA) is not a good candidate for PPy synthesis in organic aprotic solvents [42]. However, our attempts for the polymerization of pyrrole on a $\mathrm{PEK}$ coated electrode in tetrabutylammonium fluoroborate/acetonitrile, $p$-toluene sulfonate/water, camphor sulfonic acid/water electrolyte/solvent systems were not successful. Yet, the use of PTSA in acid form enables the synthesis of the composite film, most probably playing an important role in the swelling of PEK on the metal electrode. 


\subsection{Conductivity measurements}

The conductivity of the composite PEK/PPy films was found to increase as the time of electrochemical polymerization process of pyrrole increased at the constant potential of $0.5 \mathrm{~V}$ in aqueous PTSA solution. Thus, pyrrole and the electrolyte penetrate through the insulating film to reach the Pt electrode. As a result, pyrrole is electro-oxidatively polymerized and doped by the counter anion at the same time. PPy grows out of the PEK layer and produces a conducting surface. The weight percentage of PPy in the composites was determined gravimetrically by weighing the PEK coated electrodes before and after the electrolyses. It was found that the solution side of the electrode is conductive, whereas the other side is not. This behavior shows that the electrochemical polymerization yields a bilayer of which the outer layer is pure PPy. The conductivity was found to be proportional to the weight percentage of PPy present in the alloy as shown by Fig. 1 .

\subsection{Morphology of composites}

The morphology of the electrode side of the alloy film is generally smooth. On the other hand, the surface morphology of the solution side contains globular projections. The formation of PPy chains on the solution side emerges in the form of particles. By peeling the electrolytic film into two layers, one can obtain the PEK layer (next to the metal electrode) and PPy layer (solution side of the composite film). The PPy layer reveals two different morphologies. The side of the PPy layer, which was in contact with the insulating polymer layer, was smoother than the other side. Furthermore, the cross sections of the composite films were investigated.

In Fig. 2(a)-(d), 250 and 1500 magnifications of PEK/ PPy film and pure PPy (synthesized with the same conditions as the composites) are shown. As seen from Fig. 2(a) and (c) a layered structure consisting of two different phases was observed. From comparison of pure PPy and PEK/PPy it was concluded that one layer consisted of pure PPy and the other of pure PEK. The formation of the layered structure is probably due to the immiscibility of the two polymers. The electropolymerization of pyrrole occurs at the surface of the electrode and grows through the PEK film, forming a continuous layer on PEK. The cross section of PPy is uniform throughout the surface, whereas cauliflower protuberances are observed in PEK/PPy alloys. This is most unusual, since in our earlier studies with PPy and several insulating polymers (polycarbonate [19], polyamide [20], polyimide [21]) we have observed homogeneous composites of uniform conductivity and microstructures for both sides of the composite films.

\subsection{Thermal analyses}

Fig. 3 reveals the glass transition temperature of electrolytic film and a mechanical mixture of the pure polymers (a physical mixture of the two components).

The thermal analyses of PEK yield a glass transition temperature $185^{\circ} \mathrm{C}$ with $5 \%$ loss at $520^{\circ} \mathrm{C}$. Fig. 4 (b) and (c) shows the thermal gravimetry (TG) curves of the electrolytic film and the mechanical mixture. The electrolytic film shows 10 and $35 \%$ weight losses around 325 and $562{ }^{\circ} \mathrm{C}$, respectively. The TG studies of the composite show that it is simply the addition of the TG curves of the pure polymers.

\subsection{FT-IR analyses of the composites}

The FT-IR spectrum of PPy shows several bands around $3400 \mathrm{~cm}^{-1}$ ( $\mathrm{N}-\mathrm{H}$ stretching), $3110 \mathrm{~cm}^{-1}$ (aromatic $\mathrm{C}-\mathrm{H}$ stretching), $1547 \mathrm{~cm}^{-1}$ ( $\mathrm{C}=\mathrm{C}$ stretching), $1440 \mathrm{~cm}^{-1}$ ( $\mathrm{C}-\mathrm{C}$

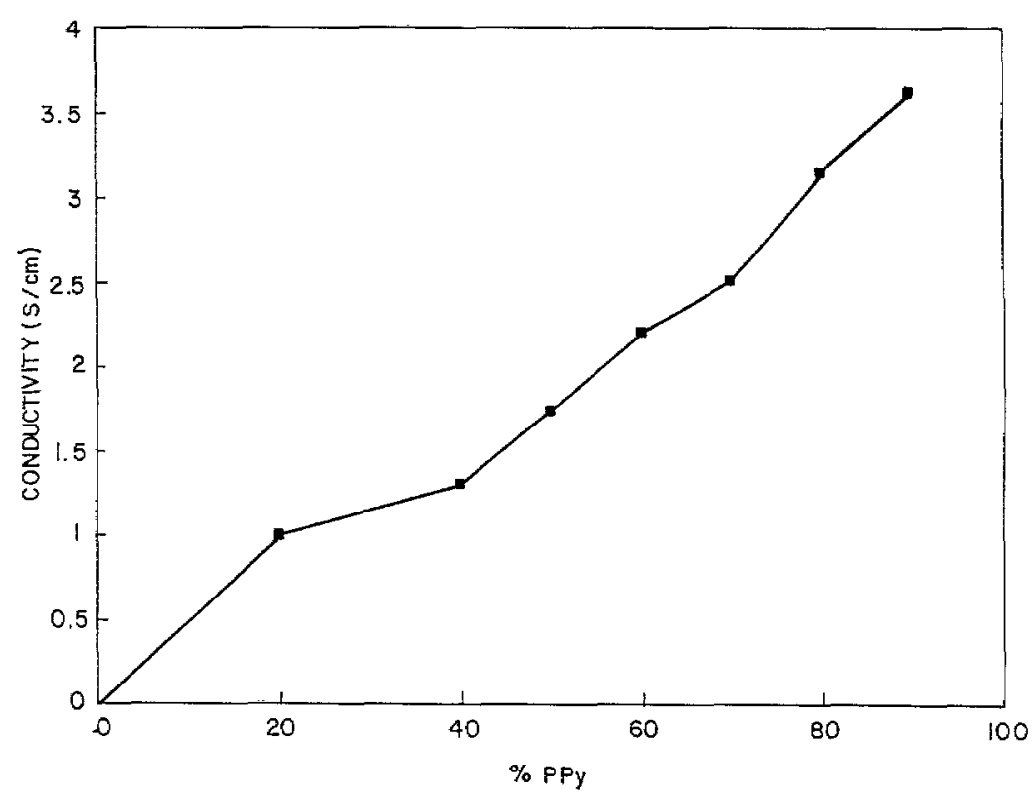

Fig. 1. Conductivity vs. \% PPy. 

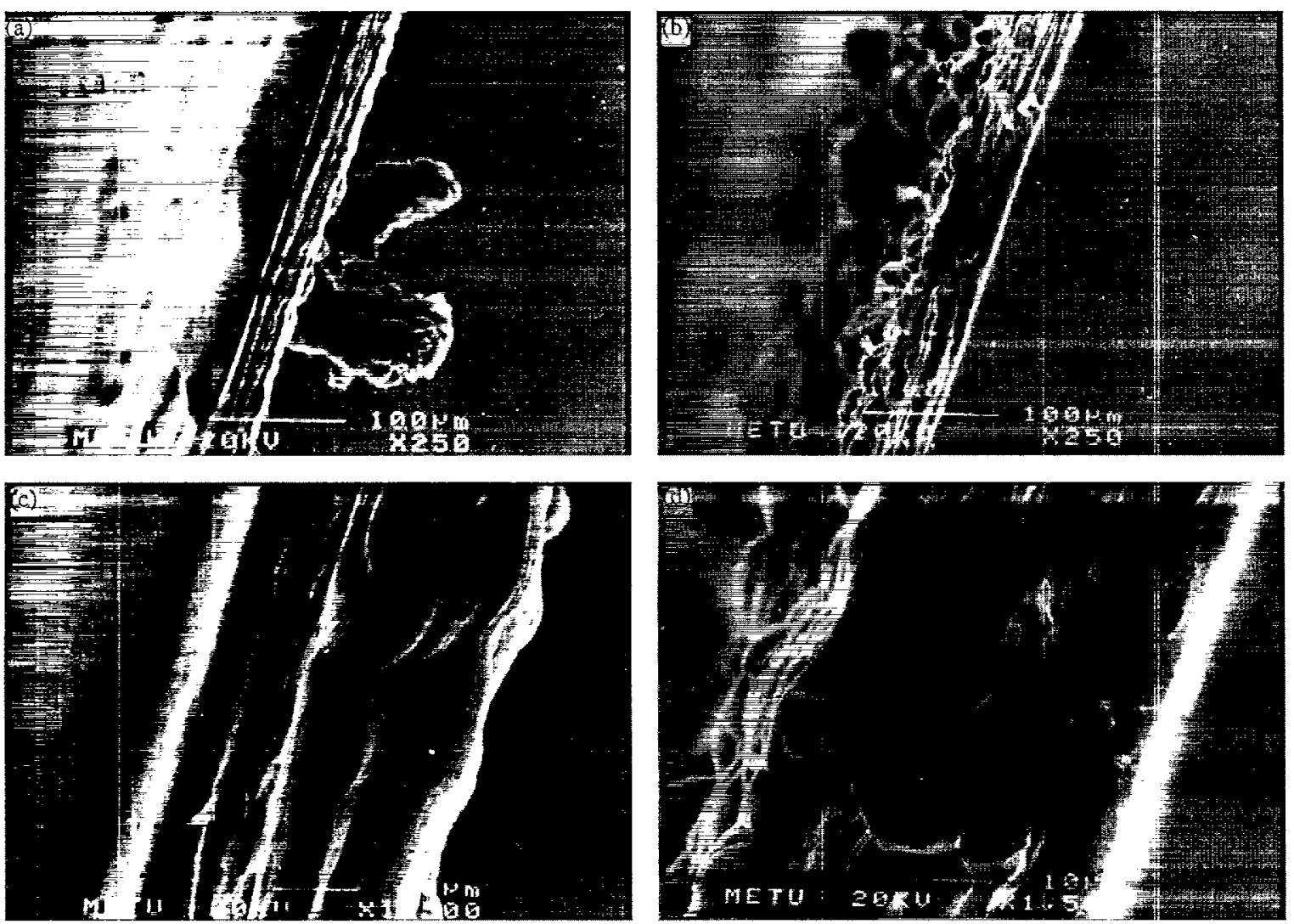

Fig. 2. SEM micrographs of cross sections: (a) composite film $(\times 250)$; (b) pure PPy $(\times 250)$; (c) composite film $(\times 1500)$; (d) pure PPy ( $\times 1500)$ (reduced in reproduction 60\%).

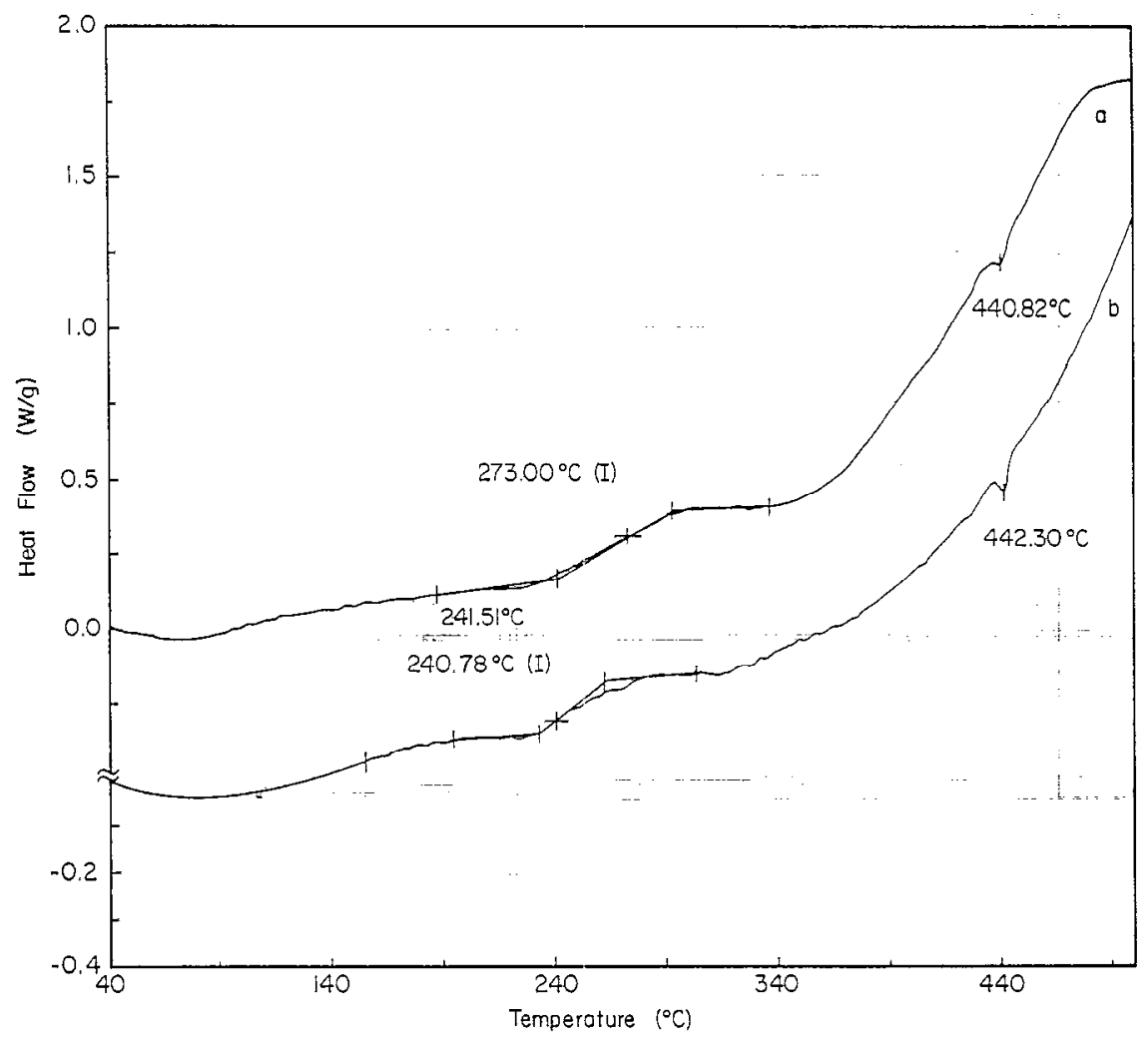

Fig. 3. Differential scanning calorimetry of (a) electrolytic film and (b) mechanical mixture. 

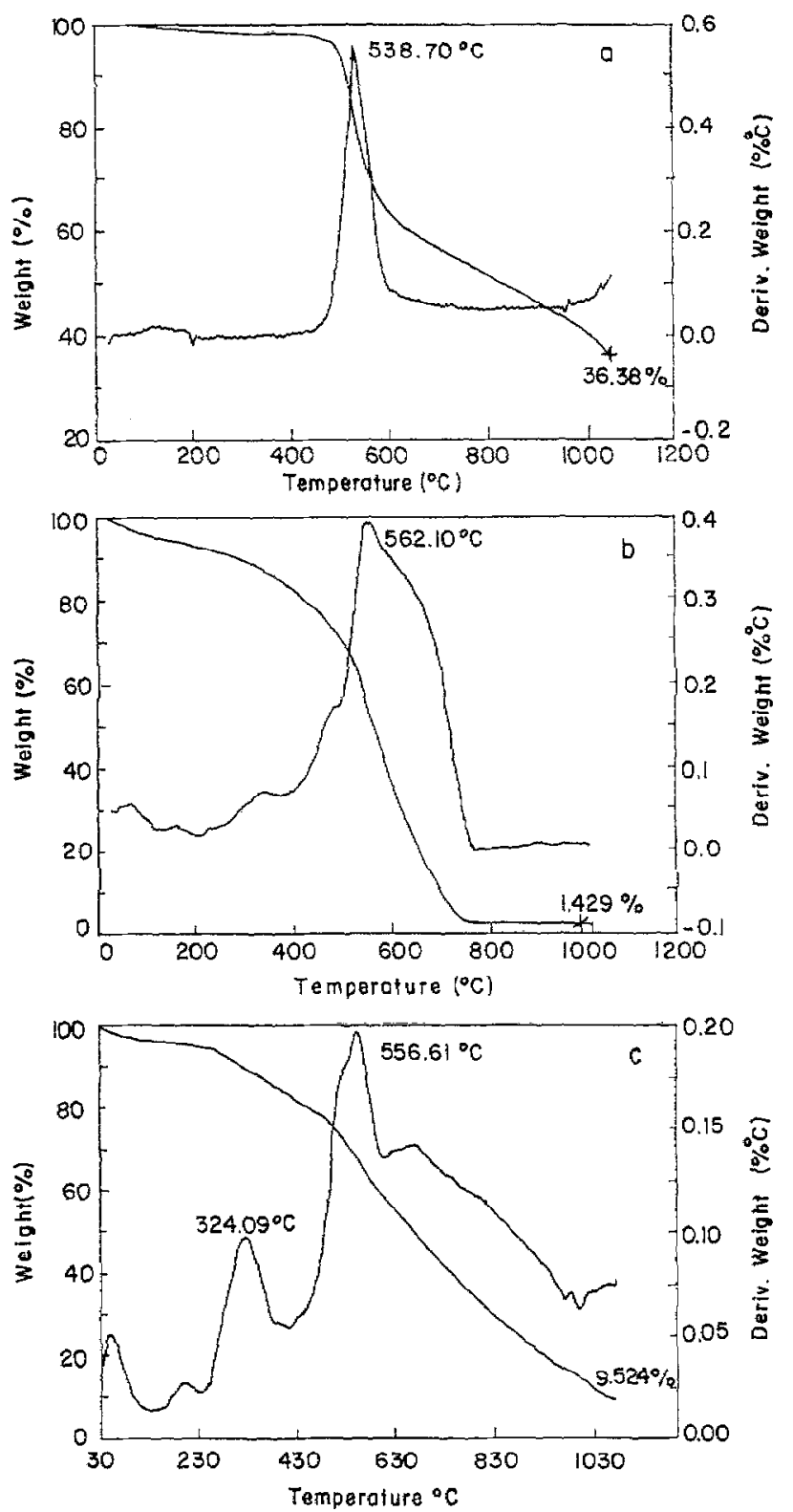

Fig. 4. TG analyses of (a) pure PEK, (b) PEK/PPy composite film and (c) mechanical mixture.

stretching), (C-N stretching), $1310 \mathrm{~cm}^{-1}$ (mixed bending and stretching vibrations associated with $\mathrm{C}-\mathrm{N}$ links), 1180 $\mathrm{cm}^{-1}$ ( $\mathrm{C}=\mathrm{N}$ stretching), $1043 \mathrm{~cm}^{-1}$ and $\mathrm{N}-\mathrm{H}$ wagging band between $909-666 \mathrm{~cm}^{-1}$. The spectrum of the electrolytic film reveals the same bands coming from pure PPy and PEK just as the spectrum of the mechanical mixture.

\subsection{CV results}

The anion doping and undoping processes for pure PPy and PEK/PPy films were investigated (Fig. 5). The experiments were performed with a potential scan from -0.1 to $+1.1 \mathrm{~V}$ on bare $\mathrm{Pt}$, and from -0.2 to $+1.2 \mathrm{~V}$ on PEK coated electrodes. The CV of pyrrole in water/PTSA medium reveals that the electroactivity decreases with increasing number of runs whether or not the metal electrode is coated
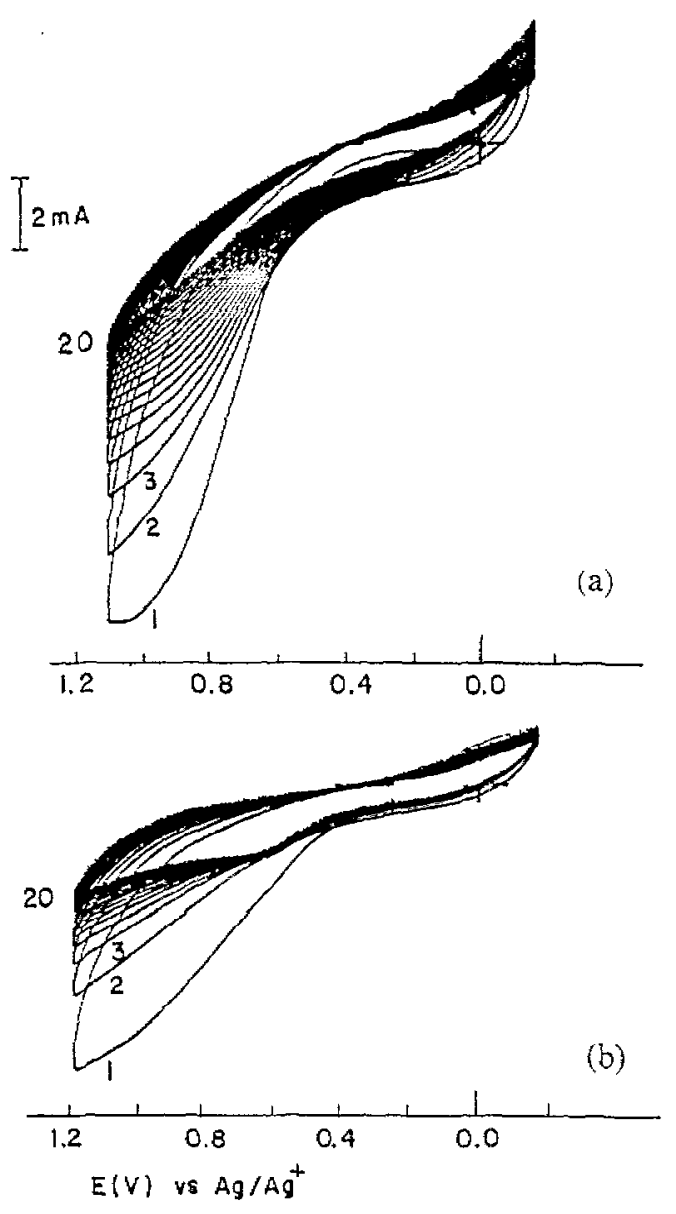

Fig. 5. Multisweep cyclic voltammograms of pyrrole (a) on bare Ptelectrode and (b) on PEK coated Pt clccirode.

with the insulating polymer. This is most probably related to the diffusion of the dopant ion in and out during doping and undoping processes since the dopant ion is relatively large compared to $\mathrm{BF}_{4}{ }^{-}[10]$.

\section{Conclusions}

By electrochemically polymerizing pyrrole in the PEK matrix we obtained composites of PPy and PEK with good environmental stability, high conductivity and good flexibility.

Based on the conductivity measurements, SEM and thermal analyses it is deduced that PEK and PPy coexist as two separate phases in the composite and no specific chemical interaction occurs between them, contrary to some cases we have come across earlier.

\section{Acknowledgements}

This work is partially supported by TBAG 1422 and DPT95K120498 grants; L.T. acknowledges TUBA support. 


\section{References}

[1] A. Shimizu, K. Yamaka and M. Kohno, Bull. Chem. Soc. Jpn., 61 (1988) 4401 .

[2] T. Shimidzu, A. Ohtani, T. Iyoda and K. Honda, J. Chem. Soc., Chem. Commun., (1987) 327.

[3] R.C.D. Peres and M.A. DePaoli, J. Puwer Sources, 40 (1992) 299.

[4] A.F. Diaz, J.I. Castillo, T.A. Logan and W. Lee, J. Electroanal. Chem., 129 (1981) 115.

[5] G. Sotzing, J.R. Reynolds and P.J. Steel, Chem. Mater., 8 (1996) 882.

[6] J.H. Borroughes, D.D.C. Bradley, A.R. Brown, R.N. Marks, K. Mackay, R.H. Friend, P.L. Burn and A.B. Holmes, Nature, 347 (1990) 539.

[7] D. Braun and A.J. Heeger, Appl. Phys. Lett., 58 (1991) 1982.

[8] F. Larmat and J.R. Reynolds, Synth. Met., 79 (1996) 229.

[9] A. Rudge, I. Raistrick, S. Gottesfeld and J.P. Ferraris, Electrochim. Acta, 39 (1994) 273.

[10] F. Selampinar, L. Toppare, U. Akbulut, T. Yalcin and S. Suzer, Synth. Met., 68 (1995) 109.

[11] J.J. Miasik, A. Hooper and B.C. Tofield, J. Chem. Soc., Faraday Trans., 82 (1986) 117.

[12] P.N. Bartlett, P.B.M. Archer and S.K. Ling-Chung, Sensors and Actuators, 19 (1989) 125.

[13] W. Schuhmann, C. Kranz, J. Huber and H. Wohlschlager, Synth. Met, $6 I$ ( 1993$) 31$.

[14] W. Schuhmann, Synth. Met., $41-43$ (1991) 429.

[15] F. Selampinar, U. Akbulut, M.Y. Ozden and L. Toppare, Biomaterials, (1997) in press.

[16] O. Niwa, M. Hikita and T. Tamamura, Makromol. Chem. Rapid Commun., 6 (1985) 375.

[17] M.A. DePaoli, R.J. Waltman, A.F. Diaz and J. Bargon, J. Polym. Sci, Polym. Chem. Ed., 23 (1985) 1687.

[18] S.E. Linsey and G.B. Street, Synth. Met., 10 (1985) 67.

[19] H.L. Wang, L. Toppare and J.E. Fernandez, Macromolecules, 23 (1990) 1053.

[20] F. Selampinar, U. Akbulut, T. Yalcin, S. Suzer and L. Toppare, Synth. Met., 62 (1994) 201.

[21] F. Selampinar, U. Akbulut and L. Toppare, Synth. Met., (1997) in press.
[22] A. Bozkurt, U. Akbulut and L. Toppare, Synth. Met., (1996) in press.

[23] R. Qian and J. Qiu, Polym. J., 19 (1987) 157.

[24] K. Koga, T. Iiona, S. Ueta and M. Takayanagi, Polym. J., 2 l (1989) 303.

[25] M. Satoh, K. Kaneto and K. Yoshino, Synth. Met., 14 (1986) 289.

[26] L.F. Warren and D.P. Anderson, J. Electrochem. Soc, 134 (1987) 101.

[27] W. Wernet, M. Monkenbusch and G. Wegner, Makromol. Chem. Rapid. Commun., 5 (1984) 157.

[28] R.C.D. Peres, V.F. Juliano, M.A. DePaoli, S. Panero and B. Scrosati, Electrochim. Acta, 38 (1993) 869

[29] R.M. Johnson, Encycl. Polym. Sci. Technol., 11 (1969) 447.

[30] R.B. Seymour and G.S. Kirshenbaum (eds.), High Performance Polymers: Their Origin and Development, Elsevier, Amsterdam, 1986.

[31] R.M. Jhonson, A.G. Farnham, R.A. Clendinning, W.F. Hale and C.N. Merriam, J. Polym. Sci. A, 5 (1967) 2375

[32] T.E. Attwood, D.A. Barr, T. King, A.B. Newton and J.B. Rose, Polymer, 18 (1977) 359.

[33] T.E. Attwood, F.C. Dawson, J.L. Freeman, L.R. Hoy, J.B. Rose and P.A. Staniland, Polymer, 22 (1981) 1096.

[34] P.M. Hergenrother, Encyclopedia of Polyner Science Engineering, Vol. 7. Wiley, New York, 2nd edn., 1985, p. 639.

[35] A.K. St. Clair, T.L. St. Clair and E.N. Smith, Polym. Prepr., 17 (1976) 359.

[36] D.K. Mohanty and J.E. McGrath, Polym. Sci. Technol, 31 (1985) 113.

[37] F. Keitoku, M. Kakimoto and Y. Imai, J. Polym. Sci., Polym. Chem., 32 (1994) 317.

[38] H.J. Jeong, M. Kakimoto and Y. Imai. J. Polym. Sci, Polym. Chem., 29 (1991) 1691 .

[39] Y. Saegusa, M. Kuriki, A. Kawai and S. Nakamura, J. Polym. Sci., Polym. Chem. 28 (1990) 3327.

[40] K. Wada, W.S. Hager, C.J. Neef, K.W. Brewer and P.E. Cassady, Polym. Prepr., 31 (1990) 35.

[41] V. Percec, M. Grigoras, R.S. Clough and J. Fanjul, J. Polym. Sci., Polym. Chem., 33 (1995) 331.

[12] R. Stankovic, O. Pavlovic, M. Vojnovic and S. Jovanok, Eur. Polym. J., 30 (1994) 385 . 